Article

\title{
Single and Multiple Inoculum of Lactiplantibacillus plantarum Strains in Table Olive Lab-Scale Fermentations
}

\author{
Barbara Lanza ${ }^{1, * \mathbb{D}}$, Miriam Zago ${ }^{2}$, Sara Di Marco ${ }^{1}$, Giuseppina Di Loreto ${ }^{1} \mathbb{D}$, Martina Cellini ${ }^{1}$, \\ Flavio Tidona ${ }^{2}$, Barbara Bonvini ${ }^{2}$, Martina Bacceli ${ }^{1}$ and Nicola Simone ${ }^{1}$ (D) \\ 1 Council for Agricultural Research and Economics (CREA), Research Centre for Engineering and Agro-Food \\ Processing (CREA-IT), Via Lombardia, 65012 Cepagatti (PE), Italy; sarettadimarco87@gmail.com (S.D.M.); \\ giuseppina.diloreto@crea.gov.it (G.D.L.); martina.cellini1992@gmail.com (M.C.); \\ martina.bacceli@crea.gov.it (M.B.); nicola.simone@crea.gov.it (N.S.) \\ 2 Council for Agricultural Research and Economics (CREA), Research Centre for Animal Production and \\ Aquaculture (CREA-ZA), Via Lombardo, 26900 Lodi (LO), Italy; miriam.zago@crea.gov.it (M.Z.); \\ flavio.tidona@crea.gov.it (F.T.); barbara.bonvini@crea.gov.it (B.B.) \\ * Correspondence: barbara.lanza@crea.gov.it
}

Received: 26 November 2020; Accepted: 14 December 2020; Published: 18 December 2020

\begin{abstract}
In order to improve the olives' quality, and to reduce the de-bittering time during the table olive fermentation process, it is necessary to pilot the fermentation by inoculating the brine with selected cultures of microorganisms. Some probiotic tests, such as resistance/sensitivity to antibiotics, bile salt hydrolase (BSH) activity, growth at acidic $\mathrm{pH}$, an auto-aggregation assay, and a test of the production of exopolysaccharides, were carried out in order to screen 35 oleuropeinolytic Lactiplantibacillus plantarum subsp. plantarum strains to be used in guided fermentations of table olives. On the basis of the technological and probiotic screening, we analyzed the progress of three different lab-scale fermentations of Olea europaea L. Itrana cv. olives inoculated with spontaneous, single, and multiple starters: jar A was left to ferment spontaneously; jar B was inoculated with a strongly oleuropeinolytic strain (L. plantarum B1); jar C was inoculated with a multiple inoculum (L. plantarum $\mathrm{B} 1+$ L. plantarum $\mathrm{B} 51+$ L. plantarum B124). The following parameters were monitored during the fermentation: $\mathrm{pH}$, titratable acidity, $\mathrm{NaCl}$ concentration, the degradation of bio-phenols, and the enrichment rate of hydroxytyrosol and tyrosol in the olive's flesh, oil and brine. The degradation of secoiridoid glucosides appeared to be faster in the inoculated jars than in the spontaneously-fermented jar. The production of hydroxytyrosol and ligstroside aglycons was high. This indicated a complete degradation of the oleuropein and a partial degradation of the ligstroside. The multiple inoculum ensured a complete debittering, and could give probiotic traits. The presence of L. plantarum B1 and B124 as a fermentation starter guarantees an optimal trend of de-bittering and fermentation variables, thus ensuring the production of a better final product. L. plantarum B51 could be considered to be a promising probiotic candidate for obtaining probiotic food of completely vegetable origin.
\end{abstract}

Keywords: L. plantarum; starter; table olives; lactic fermentation; biophenols; oleuropein; ligstroside; hydroxytyrosol; tyrosol

\section{Introduction}

Today, table olives, the most widespread traditional product of the Mediterranean area, are considered to be becoming a functional food. The growing interest in healthy foods, beside the awareness of their beneficial effects in promoting the intestinal microbial balance of the host, led to the development of many new products and improved production methods, together with an increasing consumption of 
functional probiotic foods [1,2]. In recent years, the scientific community has focused its attention on fermented foods, recognizing their important role as vehicles of probiotic microorganisms [3]. Among fermented vegetable products, table olives represent a valid source of probiotics, mainly lactic acid bacteria (LAB) [4-7] and yeasts [8,9]. These microorganisms play an important role during fermentation, and they are responsible for the acidification of the brine and for the development of the organoleptic characteristics, respectively. The spontaneous debittering is slower and unpredictable, and it is strongly influenced by physico-chemical parameters, presence of fermentable substrates, and the indigenous bacteria microbiota. The use of starter cultures with $\beta$-glucosidase positive strains was extensively applied to reduce the debittering time and to control the fermentation process [10-12]. The spontaneous fermentation of olives depends, above all, on LAB, which are mostly represented by the species Lactiplantibacillus plantarum (formerly Lactobacillus plantarum), and yeasts that prevail in the brines. In addition, LAB are capable of inhibiting the growth of undesirable microorganisms, increasing the safety of the final products [13-15]. Microorganisms such as L. plantarum accelerate this process by hydrolyzing the glycosides that are mainly responsible for the bitter taste of the olive, such as oleuropein and ligstroside. The process of oleuropein and ligstroside lysis takes place in two phases: (i) the hydrolysis of the glycosidic bond by $\beta$-glucosidase, with the formation of oleuropein or ligstroside-aglycons; (ii) the hydrolysis of the aglycons by esterase, with the formation of elenolic acid and hydroxytyrosol (from oleuropein-aglycon) or tyrosol (from ligstroside-aglycon) [10,16,17].

These findings encouraged researchers to study the use of multifunctional starter cultures in order to produce potential probiotic olives at the laboratory level, and on a large pilot scale [18]. The starter strain selection is based on their in vitro characteristics, which are mainly represented by their ability to survive in higher salt concentrations, to tolerate a wider $\mathrm{pH}$ range, to grow at low temperature, and to have $\beta$-glucosidase positivity $[11,19,20]$.

Probiotics are defined, in 2001, by the FAO and WHO as "microorganisms that, if ingested in adequate quantities, confer benefits on the host organism" [21]. Many studies describe the fact that using probiotics as a food supplement improves the intestinal flora of the host; stimulates/modulates mucosal immunity; reduces inflammatory or allergic reactions; decreases blood cholesterol levels; has anti-colon-cancer effects; reduces clinical manifestations of atopic dermatitis, Crohn's disease, diarrhea, constipation, candidiasis, and urinary tract infections; and competitively excludes pathogens [22-24]. The ability to adhere to the intestinal mucosa is considered one of the main selection criteria in the identification of potential probiotics; many studies have shown the efficiency of LAB strains isolated from different table olive cultivars, through their probiotic characterization and the simulation of all of the conditions of the entire gastrointestinal tract $[6,7]$.

A total of $35 \mathrm{~L}$. plantarum strains, isolated from naturally fermented olives, preserved in the CREA-IT.PE Collection (WDCM 945), molecularly-identified and typed, were selected on the basis of their pro-technological (oleuropeinolytic activity, $\beta$-glucosidase and esterase activity, tolerance to high $\mathrm{NaCl}$ concentrations, growth at low temperatures, acidifying activity, phage sensibility, Ca-alginate microencapsulation) and probiotic properties. The pro-technological tests were described in previous works $[10,11,25]$, while the probiotic activity was evaluated in this work. The following probiotic tests were carried out: resistance/sensitivity to seven different antibiotics (clindamycin, erythromycin, gentamicin, tetracycline, chloramphenicol, kanamycin and ampicillin), the ability to hydrolyze bile salts (GDCA-glycodeoxycholic acid, TDCA-taurodeoxycholic acid), growth at acidic $\mathrm{pH}$, an auto-aggregation assay, and a test for the production of exopolysaccharides. The aim of the present study was to analyze the progress of three different lab-scale fermentations (jars A, B, C) of Itrana olives, with and without the addition of starters, taking care to describe them under microbiological and chemical profiles. Furthermore, we wanted to investigate the probiotic characteristics of the strains inoculated in the brines, and their influence on the fermentation in order to obtain probiotic olives. 


\section{Materials and Methods}

\subsection{Bacterial Strains, Culture Media, and Growth Conditions}

Thirty-five L. plantarum strains isolated from table olive brines and preserved in the CREA-IT Collection (WDCM 945) were included in this study (Table 1). The reference strains L. plantarum Lp790 and L. bulgaricus Lb270 were isolated from Italian 'Morlacco' and 'Asiago' cheeses, respectively, and preserved in the CREA-ZA Collection. $L p 790$ was used as a reference strain for BSH and antibiotic susceptibility tests. $L b 270$ was the reference strain for the exopolysaccharide (EPS) production test.

The strains selected for the inoculum were:

- $\quad$ L. plantarum B1, isolated from olive brines [10].

- L. plantarum B51, isolated from olive brines [11,25].

- $\quad$ L. plantarum B124, isolated from olive brines [11,25].

All of the the strains were maintained as frozen stocks at $-80{ }^{\circ} \mathrm{C}$ in the presence of $150 \mathrm{~mL} / \mathrm{L}$ glycerol as a cryoprotective agent, and were reactivated overnight at $30^{\circ} \mathrm{C}$ in MRS broth (Thermo Scientific ${ }^{\mathrm{TM}}$ Oxoid ${ }^{\mathrm{TM}}$, Waltham, MA, USA) before use.

Table 1. Bacterial strains and plant origin of the fermenting brines.

\begin{tabular}{|c|c|}
\hline Strain Number & Origin (Olea europaea L. cv.) \\
\hline B1 & unknown \\
\hline $\mathrm{B} 2$ & unknown \\
\hline B3 & $\mathrm{I}-77$ \\
\hline B4 & Carolea \\
\hline B7 & unknown \\
\hline B8 & unknown \\
\hline B10 & Ascolana tenera \\
\hline B12 & Picholine \\
\hline B13 & Picholine \\
\hline B14 & Nocellara del Belice \\
\hline B15 & Picholine \\
\hline B17 & Leccino \\
\hline B19 & Sant'Agostino \\
\hline B21 & Sant'Agostino \\
\hline $\mathrm{B} 23$ & Nocellara del Belice \\
\hline B25 & Coratina \\
\hline $\mathrm{B} 27$ & Coratina \\
\hline B28 & Coratina \\
\hline B31 & $\mathrm{I}-77$ \\
\hline B39 & Grossa di Cassano \\
\hline B44 & Santa Caterina \\
\hline B51 & Cucco \\
\hline B53 & Cucco \\
\hline B124 & Sant'Agostino \\
\hline
\end{tabular}


Table 1. Cont.

\begin{tabular}{cc}
\hline Strain Number & Origin (Olea europaea L. cv.) \\
\hline B126 & Nocellara del Belice \\
\hline B130 & Ascolana tenera \\
\hline B136 & Nocellara del Belice \\
\hline B137 & Nocellara etnea \\
\hline B138 & Bella di Cerignola \\
\hline B142 & Intosso \\
\hline B146 & Ascolana tenera \\
\hline B158 & Sant'Agostino \\
\hline B160 & Bella di Cerignola \\
\hline B162 & Nocellara del Belice \\
\hline B165 & Nocellara etnea \\
\hline
\end{tabular}

\subsection{Probiotic Characterization of the Starter Cultures}

\subsubsection{Growth at Acidic $\mathrm{pH}$}

The growth at acidic $\mathrm{pH}$ was evaluated by inoculating the bacterial strains in MRS broth at $\mathrm{pH}$ 2.0. After $48 \mathrm{~h}$ of incubation at $30^{\circ} \mathrm{C}$, the bacterial suspension was centrifuged (ALC PK 120R; Thermo Electron Corporation, Waltham, MA, USA) at $3500 \mathrm{rpm}$ for $5 \mathrm{~min}$. The resulting pellet was re-suspended in deionized water, and then the absorbance at $600 \mathrm{~nm}\left(\mathrm{~A}_{600}\right)$ was measured with a Lambda 25 UV/Vis spectrometer (Perkin Elmer, Waltham, MA, USA).

\subsubsection{Bile Salt Hydrolase (BSH) Activity}

The BSH activity was detected through a direct plate assay method. L. plantarum strains were grown overnight in MRS broth and, for each strain, $10 \mu \mathrm{L}$ this culture was spotted onto four sector plates containing MRS agar (Thermo Scientific ${ }^{\mathrm{TM}}$ Oxoid $^{\mathrm{TM}}$, Waltham, MA, USA), MRS agar $+\mathrm{CaCl}_{2}$ supplemented with glycodeoxyocholic acid (GDCA; Thermo Scientific ${ }^{\mathrm{TM}}$ Oxoid $^{\mathrm{TM}}$, Waltham, MA, USA), and MRS agar $+\mathrm{CaCl}_{2}$ supplemented with taurodeoxycholic acid (TDCA; Thermo Scientific ${ }^{\mathrm{TM}}$ Oxoid ${ }^{\mathrm{TM}}$, Waltham, MA, USA). L. plantarum 790 was employed as the positive control. The Petri plates were then anaerobically incubated at $37^{\circ} \mathrm{C}$ for $72 \mathrm{~h}$. The BSH activity was indicated when the hydrolyzed products of the acid-glycine or taurine-precipitated in the agar medium in and around the spots.

\subsubsection{Antibiotic Susceptibility}

The antibiotic susceptibility profile of the LAB was tested through the involvement of seven antibiotics commonly used in antibiogram analysis (gentamicin, erythromycin, clindamycin, tetracycline, chloramphenicol, ampicillin and kanamycin; Merck, Darmstadt, Germany). It was examined by the micro-dilution broth test described by the EFSA in the 'Guidance of the assessment of bacterial antimicrobial susceptibility'. The strains grew in LSM broth medium consisting of $90 \%$ Iso-Sensitest (IS; Thermo Scientific $^{\mathrm{TM}}$ Oxoid $^{\mathrm{TM}}$, Waltham, MA, USA) and $10 \%$ MRS. The inoculum was standardized with the Thoma chamber in order to obtain a final concentration of $10^{6} \mathrm{CFU} / \mathrm{mL}$. The dilutions of the strain were performed in Ringer's solution (Thermo Scientific ${ }^{\mathrm{TM}}$ Oxoid $^{\mathrm{TM}}$, Waltham, MA, USA). LAB were then inoculated into LSM medium containing different concentrations of each antimicrobial agent in a 96-well polystyrene microtitre sterile plate. In the first column, $190 \mu \mathrm{L}$ medium at the highest concentration of antibiotics was dispensed, then $95 \mu \mathrm{L}$ antibiotic-free medium was delivered into the others (from column 2 to 11), while only $100 \mu \mathrm{L}$ medium was distributed into the 12th (negative control). From the first column, scalar dilutions were carried out. All of the wells were inoculated 
(except for the negative control) with $5 \mu \mathrm{L}$ the standardized bacterial culture. The growth was assessed after incubation for $24-48 \mathrm{~h}$ at $37^{\circ} \mathrm{C}$, and the MIC value was read. The MIC, expressed in $\mu \mathrm{g} / \mathrm{mL}$, is the lowest concentration that inhibits visual growth; it was established that resistance occurred when the minimum inhibitory concentration (MIC) was greater than the breakpoint value.

\subsubsection{Exopolysaccharide (EPS) Production}

The presence of EPSs surrounding the bacterial surface was detected by Scanning Electron Microscopy (SEM). The cultures were fixed for $12 \mathrm{~h}$ at $4{ }^{\circ} \mathrm{C}$ in $2.5 \%$ glutaraldehyde in $0.1 \mathrm{M} \mathrm{Na}$-cacodylate buffer ( $\mathrm{pH} 7.4)$, and then filtered $(0.45-\mu \mathrm{m}$ pore size). The samples were washed with the same buffer, dehydrated in ethanol series (30,50,70, 85, 95 and 100\%), then transferred to $100 \%$ acetone before drying with $\mathrm{CO}_{2}$ at the critical point in a Critical Point Dryer CPD 030 (Balzers Union, Balzers, Liechtenstein). The dry filters were then mounted on aluminum stubs and coated with gold (20 nm thick) in a Sputter Coater SCD 050 (Balzers Union). Representative specimens were examined with a Philips XL 20 SEM (FEI Europe, Eindhoven, The Netherlands) and then photographed.

Each strain was also controlled for viscosity. The strains were revitalized and grown in MRS broth at $30^{\circ} \mathrm{C}$ for $18 \mathrm{~h}$. The apparent viscosity was measured by means of a rotary viscometer series MYR VR 3000 (Viscotech Hispania, Tarragona, Spain). After stirring the medium for $30 \mathrm{~s}$, viscosity measurements were taken at $30^{\circ} \mathrm{C}$ at different rotation speeds (20, 30, 50, 60, 100 and 200 rpm) [26]. The mucosity was also evaluated on single colony grown in MRS agar.

\subsubsection{Auto-Aggregation Assay}

The auto-aggregation assays were performed according to the methodology described by Bautista-Gallego et al. [6]. The auto-aggregation percentage was expressed as a function of time using the formula $1-\left(\mathrm{At} / \mathrm{A}_{0}\right) \times 100$, in which At represents the absorbance at $5 \mathrm{~h}$ and $\mathrm{A}_{0}$ represents the absorbance at time $0 \mathrm{~h}$.

\subsection{Table Olive Processing}

\subsubsection{Raw Olives and Microorganisms}

The fruits of Olea europaea L. Itrana cv. were hand-harvested at their mature-green stage of ripening (1.04 Jaen Index) during December 2019, and were supplied by the farm Frantoio Oleario F.lli Feudi, located in Sonnino (LT), Italy. The olives were divided into three lots of $2700 \mathrm{~g}$ olives (about 700 drupes) and placed in three glass jars, then submerged in $8 \%$ brine prepared with $80 \mathrm{~g} / \mathrm{L}$ of sterilized Trapani PGI sea salt, following the Greek-style method [27]. Three different fermentations were evaluated: A, spontaneous fermentation; B, fermentation with a single inoculum (L. plantarum B1); C, fermentation with multiple inoculum (L. plantarum B1 + L. plantarum B51 + L. plantarum B124, 1:1:1).

\subsubsection{Preparation of the Inocula}

The bacterial precultures of L. plantarum B1 $(5 \mathrm{~mL})$ were transferred into flasks of $100 \mathrm{~mL}$ MRS broth and incubated for $24 \mathrm{~h}$ at $30^{\circ} \mathrm{C}$ in order to obtain the inoculum biomass; the cells were centrifuged (ALC PK 120R; Thermo Electron Corporation, Waltham, MA, USA) at $3500 \mathrm{rpm}$ for $15 \mathrm{~min}$ at $15^{\circ} \mathrm{C}$, and the pellet was re-suspended in $100 \mathrm{~mL}$ sterilized brine ( $80 \mathrm{~g} / \mathrm{L}$ of Trapani PGI sea salt).

The bacterial precultures of L. plantarum B1 (2.5 mL), L. plantarum B51 (2.5 mL), and L. plantarum B124 (2.5 mL) were transferred into flasks of $50 \mathrm{~mL}$ MRS broth and incubated for $24 \mathrm{~h}$ at $30{ }^{\circ} \mathrm{C}$ in order to obtain the inoculum biomass; the cells were centrifuged (ALC PK 120R; Thermo Electron Corporation, Waltham, MA, USA) at $3500 \mathrm{rpm}$ for $15 \mathrm{~min}$ at $15^{\circ} \mathrm{C}$, and each pellet was re-suspended in $33.3 \mathrm{~mL}$ sterilized brine ( $80 \mathrm{~g} / \mathrm{L}$ of Trapani PGI sea salt). Every culture was collected and grouped (1:1:1) in order to reach a final inoculum volume of $100 \mathrm{~mL}$.

After $72 \mathrm{~h}$ from the immersion of the olives in the brine, each bacterial culture mixture (inoculum level: $6 \mathrm{log} / \mathrm{mL}$ ) was distributed into the glass jars and then incubated at room temperature. The olive 
fermentation process was considered complete after 8 months. The sampling was performed during the breadth of the fermentation process, after 10, 20, 30, 60, 150, 180 and 240 days. The study was conducted in duplicate.

\subsubsection{Determination of the Cell Viability during the Fermentation}

The cell population of the olive starters was determined after 10, 20, 30, 60, 150 and 180 days. Serial dilutions of fermentation brines were plated on MRS agar and incubated at $30{ }^{\circ} \mathrm{C}$ for $48 \mathrm{~h}$ in an anaerobic atmosphere for the enumeration of the total lactic acid bacteria in each jar. Anaerobic culture jars and AnaeroGen AN 35 sachets (Thermo Scientific ${ }^{\mathrm{TM}}$ Oxoid ${ }^{\mathrm{TM}}$, Waltham, MA, USA) were used for the creation of the anaerobic conditions. Simultaneously, plates were incubated at $37^{\circ} \mathrm{C}$ for $24 \mathrm{~h}$ in aerobiosis in MacConkey agar medium (Thermo Scientific ${ }^{\mathrm{TM}}$ Oxoid ${ }^{\mathrm{TM}}$, Waltham, MA, USA) for the monitoring of the Enterobacteriaceae, and at $30{ }^{\circ} \mathrm{C}$ for $48 \mathrm{~h}$ in aerobiosis in Malt Extract Agar (Thermo Scientific $^{\mathrm{TM}}$ Oxoid ${ }^{\mathrm{TM}}$, Waltham, MA, USA) for the detection of yeasts. The results are expressed as colony-forming units (CFU) per $\mathrm{mL}$ olive brine, and were recorded for plates containing 20 to 350 colonies.

\subsubsection{Evaluation of the Physicochemical Properties of the Fermentation Brines}

The $\mathrm{pH}$ was measured by electrode immersion with an Istek pH Meter 730P model (Istek, Inc., Seoul, Korea). The titratable acidity was determined by the titration of $10 \mathrm{~mL}$ brine with $0.1 \mathrm{~N} \mathrm{NaOH}$, using phenolphthalein $1 \%$ as the indicator. The results are expressed as grams of lactic acid per $100 \mathrm{~mL}$ olive brine. The salinity was determined by the titration of $1 \mathrm{~mL}$ brine, diluted with $9 \mathrm{~mL}$ distilled water, with silver nitrate $0.1 \mathrm{~N}$, using $100 \mu \mathrm{L}$ potassium chromate as the indicator. The data are expressed as grams of $\mathrm{NaCl}$ per $100 \mathrm{~mL}$ brine.

\subsubsection{Evaluation of the Physicochemical Properties of the Olive Juice}

The juice fraction was obtained from the filtration of olive flesh using a vacuum pump equipped with an apparatus for membrane filtration that includes a filter consisting of 80-denier nylon mesh pantyhose. The titratable acidity and salinity were determined for the olive juice as described for the brines.

\subsection{Biophenols Composition by HPLC}

In total, 30 olive fruits were manually de-pitted and triturated with a grinder. The olive paste was warmed up in a water bath at $28 \pm 2{ }^{\circ} \mathrm{C}$ for $30 \mathrm{~min}$, and then centrifuged at $3500 \mathrm{rpm}$ for $30 \mathrm{~min}$ at $10^{\circ} \mathrm{C}$ in a refrigerated centrifuge (ALC PK 120R; Thermo Electron Corporation, Waltham, MA, USA). The resulting supernatant oil was collected with a Pasteur pipette and filtered in the presence of anhydrous sodium sulphate, and then stored in $50 \mathrm{~mL}$ Falconßplastic tubes (Thermo Fisher Scientific Inc., Waltham, MA, USA) wrapped with aluminum foil, which was kept at $4{ }^{\circ} \mathrm{C}$ until the analysis. This procedure simulates the extraction of olive oil in olive mills (i.e., crushing, mixing and centrifugation), and it was used with the aim of preventing changes in the oil quality as best as possible.

In order to prepare the olive flesh extracts, $0.5 \mathrm{~g}$ of homogenized flesh was transferred into a test tube with $1 \mathrm{~mL}$ internal standard (syringic acid $0.015 \mathrm{mg} / \mathrm{mL}$ in methanol) and vortexed for $30 \mathrm{~s}$. The mixture was added with $5 \mathrm{~mL}$ methanol/water 80/20, vortexed for $1 \mathrm{~min}$, sonicated in an ultrasonic bath for $15 \mathrm{~min}$, and centrifuged at $3500 \mathrm{rpm}$ for $5 \mathrm{~min}$. An aliquot of the supernatant $(1 \mathrm{~mL})$ was filtered in a $0.45 \mu \mathrm{m}$ PVDF membrane (Merck, Darmstadt, Germany), and then a $20 \mu \mathrm{L}$ volume was injected into a LC 200 High Resolution Liquid Chromatograph (HPLC) equipped with a Series $200 \mathrm{UV} /$ Vis detector (Perkin Elmer, Waltham, MA, USA), a 7725 Rheodyne injector, a $20 \mu \mathrm{L}$ sample loop and a Totalchrom workstation (Perkin Elmer, Waltham, MA, USA) for data acquisition.

In order to prepare the olive oil extracts, $2.5 \mathrm{~g}$ oil was added to $500 \mu \mathrm{L}$ internal standard solution (syringic acid $0.015 \mathrm{mg} / \mathrm{mL}$ in methanol). After the removal of the methanol under reduced pressure at 
a temperature of $<35^{\circ} \mathrm{C}$, the sample was dissolved in $6 \mathrm{~mL}$ hexane and loaded onto a SPE column (Discovery DSCDIOL $500 \mathrm{mg}, 3 \mathrm{~mL}$; Supelco, Bellefonte, PA, USA), previously conditioned with $6 \mathrm{~mL}$ methanol and $6 \mathrm{~mL}$ hexane. The sample was then subjected to washing with $2 \times 3 \mathrm{~mL}$ hexane and $4 \mathrm{~mL}$ hexane/ethyl acetate 90/10, and then extracted with $10 \mathrm{~mL}$ methanol. After the removal of the methanol with a rotary evaporator at a temperature of $<35^{\circ} \mathrm{C}$, the dry residue was taken up with $1 \mathrm{~mL}$ methanol/water 50/50, and $20 \mu \mathrm{L}$ was injected into the HPLC system after filtration on a $0.45 \mu \mathrm{m}$ PVDF membrane.

The HPLC analysis of the phenolic extracts was carried out according to the methodology described by Lanza et al. [28]. The quantification of the phenolic compounds, expressed as tyrosol according to COI/T.20/Doc No 29/2009 [29], was performed according to the concentration of the internal standard and on the basis of the response factor of syringic acid to tyrosol. All of the analyses were carried out in duplicate for each sample.

Simultaneously with the analysis of the olive extracts, the phenol composition of the fermentation brine was monitored. A volume of $1 \mathrm{~mL}$ brine was dissolved in $5 \mathrm{~mL}$ methanol/water 80/20 and filtered through a $0.45 \mu \mathrm{m}$ PVDF membrane. Finally, $20 \mu \mathrm{L}$ of the sample solution was directly injected into the HPLC system.

\section{Results}

\subsection{Probiotic Characterization of Starter Cultures}

Table 2 shows the results of the probiotic characterization of all 35 strains. All of the strains, except B15 and B31, weren't inhibited in growth by pH 2.0 (Table 2).

Twelve strains demonstrated a slightly positive ability to hydrolyze sodium salt of glycodeoxycholic acid (GDCA), while a single strain (B51) showed the positive ability to hydrolyze sodium salt of taurodeoxycholic acid (TDCA) (Table 2).

All of the strains, except B19, were resistant to ampicillin and kanamycin, and susceptible to erythromycin, tetracycline and chloramphenicol; four lactobacilli were also resistant to gentamicin (L. plantarum B4, B13, B17 and B51), and one strain (B28) was resistant to clindamycin (Table 2).

All of the strains have very low viscosity values, measured at $60 \mathrm{rpm}$ in MRS broth as a liquid matrix (Table 2), and the colonies do not appear mucous. The production of exopolysaccharides (EPSs) was ascertained only in B51 by the morphological aspect through Scanning Electron Microscopy (SEM) (Figure 1). The EPSs were visualized as intercellular connections formed by thin filaments, approximately $200 \AA$ in diameter. Scanning Electron Microscopy proved to be a good method for the detection of the bacteria capable of producing exopolysaccharides that could play an essential role during cell adhesion and biofilm formation [30]. L. plantarum B51, despite the low viscosity values found, seems to be a good EPS-producing bacterium.

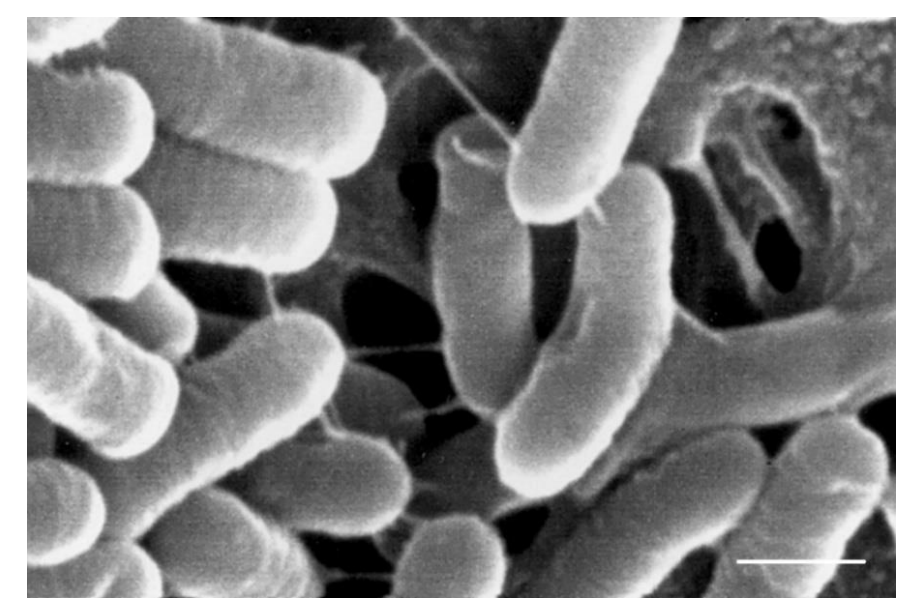

Figure 1. SEM image of exopolysaccharide (EPS)-production by L. plantarum B51. Bar $=0.7 \mu \mathrm{m}$. 
Table 2. Probiotic characterization of the LAB starter.

\begin{tabular}{|c|c|c|c|c|c|c|c|c|c|c|c|c|c|}
\hline \multirow[t]{2}{*}{ Strain } & \multirow{2}{*}{$\begin{array}{c}\text { Growth at } \\
\text { Acidic pH } \\
\text { pH } 2.0\end{array}$} & \multicolumn{2}{|c|}{ Bile Salt Hydrolysis } & \multicolumn{7}{|c|}{ Antibiotic Susceptibility (MIC *) } & \multicolumn{3}{|c|}{ Exopolysaccharides Production } \\
\hline & & TDCA & GDCA & Clindamycin & Erythromycin & Gentamicin & Tetracycline & Chloramphenicol & Ampicillin & Kanamycin & $\begin{array}{l}\text { Colony } \\
\text { Mucosity }\end{array}$ & $\begin{array}{l}\text { Culture Viscosity } \\
\text { (mPa.s) }\end{array}$ & $\begin{array}{l}\text { Visualization of } \\
\text { EPSs by SEM }\end{array}$ \\
\hline B1 & +++ & - & - & $2(\mathrm{~S})$ & $0.25(\mathrm{~S})$ & $16(\mathrm{~S})$ & $32(\mathrm{~S})$ & $8(S)$ & $8(\mathrm{R})$ & $256(\mathrm{R})$ & absent & 1.11 & absent \\
\hline B2 & +++ & - & - & 2 (S) & 0.25 (S) & 16 (S) & $32(\mathrm{~S})$ & $8(\mathrm{~S})$ & $8(\mathrm{R})$ & $256(\mathrm{R})$ & absent & 1.06 & absent \\
\hline B3 & + & - & - & 2 (S) & $0.5(\mathrm{~S})$ & $16(\mathrm{~S})$ & 32 (S) & 8 (S) & $8(\mathrm{R})$ & $256(\mathrm{R})$ & absent & 1.06 & absent \\
\hline B4 & ++ & - & - & $1(\mathrm{~S})$ & $0.5(\mathrm{~S})$ & $32(\mathrm{R})$ & $32(\mathrm{~S})$ & $8(S)$ & $8(\mathrm{R})$ & 256 (R) & absent & 1.18 & absent \\
\hline B7 & ++ & - & - & 2 (S) & 0.25 (S) & 16 (S) & 32 (S) & $8(\mathrm{~S})$ & $8(\mathrm{R})$ & $256(\mathrm{R})$ & absent & 1.21 & absent \\
\hline B8 & ++ & - & - & 2 (S) & 0.25 (S) & 16 (S) & $32(\mathrm{~S})$ & 8 (S) & $8(\mathrm{R})$ & 256 (R) & $+/-$ & 1.09 & absent \\
\hline B10 & ++ & - & - & 1 (S) & 0.25 (S) & 16 (S) & $32(\mathrm{~S})$ & $8(\mathrm{~S})$ & $8(\mathrm{R})$ & $256(\mathrm{R})$ & absent & 1.18 & absent \\
\hline B12 & ++ & - & - & 2 (S) & 0.5 (S) & 16 (S) & 32 (S) & 8 (S) & 8 (R) & 256 (R) & $+/-$ & 1.09 & absent \\
\hline B13 & ++ & - & + & $1(\mathrm{~S})$ & $0.25(\mathrm{~S})$ & $32(\mathrm{R})$ & 32 (S) & 8 (S) & $8(\mathrm{R})$ & $256(\mathrm{R})$ & $+/-$ & 1.2 & absent \\
\hline B14 & ++ & - & + & 1 (S) & 0.25 (S) & 16 (S) & 32 (S) & 8 (S) & $8(\mathrm{R})$ & $256(\mathrm{R})$ & absent & 1.1 & absent \\
\hline B15 & - & - & - & 1 (S) & 0.25 (S) & 16 (S) & 32 (S) & 8 (S) & $8(\mathrm{R})$ & 256 (R) & $+/-$ & 1.2 & absent \\
\hline B17 & +++ & - & + & 2 (S) & 0.25 (S) & $32(\mathrm{R})$ & 32 (S) & 8 (S) & $8(\mathrm{R})$ & $256(\mathrm{R})$ & absent & 1.22 & absent \\
\hline B19 & ++ & - & - & 2 (S) & 0.25 (S) & 16 (S) & 32 (S) & 8 (S) & 8 (S) & 256 (S) & $+/-$ & 1.3 & absent \\
\hline B21 & +++ & - & - & 2 (S) & 0.25 (S) & 16 (S) & 32 (S) & 8 (S) & $4(\mathrm{R})$ & 256 (R) & absent & 1.09 & absent \\
\hline B23 & ++ & - & - & 1 (S) & 0.25 (S) & 16 (S) & 32 (S) & 8 (S) & $4(\mathrm{R})$ & $256(\mathrm{R})$ & absent & 1.16 & absent \\
\hline B25 & + & - & - & 2 (S) & 0.25 (S) & 16 (S) & 32 (S) & 8 (S) & $4(\mathrm{R})$ & 256 (R) & absent & 1.09 & absent \\
\hline B27 & ++ & - & + & 2 (S) & 0.25 (S) & 16 (S) & $32(\mathrm{~S})$ & $8(\mathrm{~S})$ & $8(\mathrm{R})$ & 256 (R) & absent & 1.08 & absent \\
\hline B28 & + & - & - & $4(\mathrm{R})$ & 0.5 (S) & 16 (S) & 32 (S) & 8 (S) & $8(\mathrm{R})$ & 512 (R) & $+/-$ & 1.3 & absent \\
\hline B31 & - & - & - & 2 (S) & 0.25 (S) & 16 (S) & 32 (S) & 8 (S) & $8(\mathrm{R})$ & 256 (R) & $+/-$ & 1.2 & absent \\
\hline B39 & ++ & - & - & 2 (S) & 0.25 (S) & $16(S)$ & 32 (S) & $8(S)$ & $8(\mathrm{R})$ & 256 (R) & $+/-$ & 1.2 & absent \\
\hline B44 & ++ & - & + & 2 (S) & 0.25 (S) & 16 (S) & 32 (S) & 8 (S) & $8(\mathrm{R})$ & 256 (R) & $+/-$ & 1.3 & absent \\
\hline B51 & ++ & ++ & ++ & 0.25 (S) & 0.5 (S) & $32(\mathrm{R})$ & 32 (S) & 8 (S) & $16(\mathrm{R})$ & $512(\mathrm{R})$ & absent & 1.12 & [see Figure 1] \\
\hline B53 & ++ & - & + & $2(\mathrm{~S})$ & 0.25 (S) & 16 (S) & 32 (S) & 8 (S) & $8(\mathrm{R})$ & 256 (R) & absent & 1.1 & absent \\
\hline B124 & +++ & - & - & $2(\mathrm{~S})$ & $1(\mathrm{~S})$ & 16 (S) & 32 (S) & 8 (S) & $8(\mathrm{R})$ & $256(\mathrm{R})$ & absent & 1.03 & absent \\
\hline B126 & +++ & - & + & 2 (S) & 0.5 (S) & 16 (S) & 32 (S) & 8 (S) & $8(\mathrm{R})$ & 256 (R) & absent & 1.24 & absent \\
\hline B130 & +++ & - & - & 2 (S) & 0.5 (S) & 16 (S) & 32 (S) & 8 (S) & $8(\mathrm{R})$ & $256(\mathrm{R})$ & absent & 1.21 & absent \\
\hline B136 & +++ & - & - & 2 (S) & $0.5(\mathrm{~S})$ & 16 (S) & 32 (S) & 4 (S) & $8(\mathrm{R})$ & 256 (R) & absent & 1.07 & absent \\
\hline B137 & +++ & - & - & 2 (S) & $0.25(\mathrm{~S})$ & 16 (S) & 32 (S) & 8 (S) & $4(\mathrm{R})$ & 256 (R) & $+/-$ & 1.12 & absent \\
\hline B138 & +++ & - & + & 2 (S) & 0.5 (S) & 16 (S) & 32 (S) & 8 (S) & $8(\mathrm{R})$ & $256(\mathrm{R})$ & $+/-$ & 1.17 & absent \\
\hline B142 & +++ & - & - & 2 (S) & 0.5 (S) & 16 (S) & 32 (S) & 8 (S) & $8(\mathrm{R})$ & 256 (R) & absent & 1.17 & absent \\
\hline B146 & ++ & - & + & 2 (S) & 0.5 (S) & 16 (S) & 32 (S) & 8 (S) & $8(\mathrm{R})$ & 256 (R) & absent & 1.17 & absent \\
\hline B158 & T+ & - & + & 0.5 (S) & 0.25 (S) & 16 (S) & 32 (S) & 8 (S) & 8 (R) & 256 (R) & $+/-$ & 1.16 & absent \\
\hline B160 & ++ & - & + & 1 (S) & 0.25 (S) & $16(\mathrm{~S})$ & $32(\mathrm{~S})$ & 8 (S) & $8(\mathrm{R})$ & 256 (R) & absent & 1.18 & absent \\
\hline B162 & +++ & - & - & 1 (S) & 0.25 (S) & 17 (S) & $32(\mathrm{~S})$ & 8 (S) & $8(\mathrm{R})$ & $256(\mathrm{R})$ & absent & 1.52 & absent \\
\hline B165 & +++ & - & - & 2 (S) & 0.5 (S) & 16 (S) & 32 (S) & 8 (S) & $8(\mathrm{R})$ & 256 (R) & $+/-$ & 1.15 & absent \\
\hline Lp 790 & + & ++ & ++ & 0.25 (S) & 0.25 (S) & 16 (S) & 32 (S) & 4 (S) & $8(\mathrm{R})$ & 64 (S) & & & absent \\
\hline Lb 270 & & & & & & & & & & & + & 1.29 & absent \\
\hline
\end{tabular}

- , negative; + , slightly positive; ++ , positive; +++ , strongly positive; ${ }^{*}$, minimum inhibitory concentration expressed in $\mu \mathrm{g} / \mathrm{mL} ; \mathrm{R}=$ resistant; $\mathrm{S}=$ susceptible. 
The results obtained from the auto-aggregation assays (Figure 2) showed that most LAB had a strong auto-aggregating phenotype, with five strains-B1, B130, B23, B4 and B126-showing the highest auto-aggregation values (more than $80 \%$ ), the largest number of strains being included in the interval between $20 \%$ and $80 \%$, while ten strains showed values below $20 \%$, and seven strains showed no auto-aggregation.

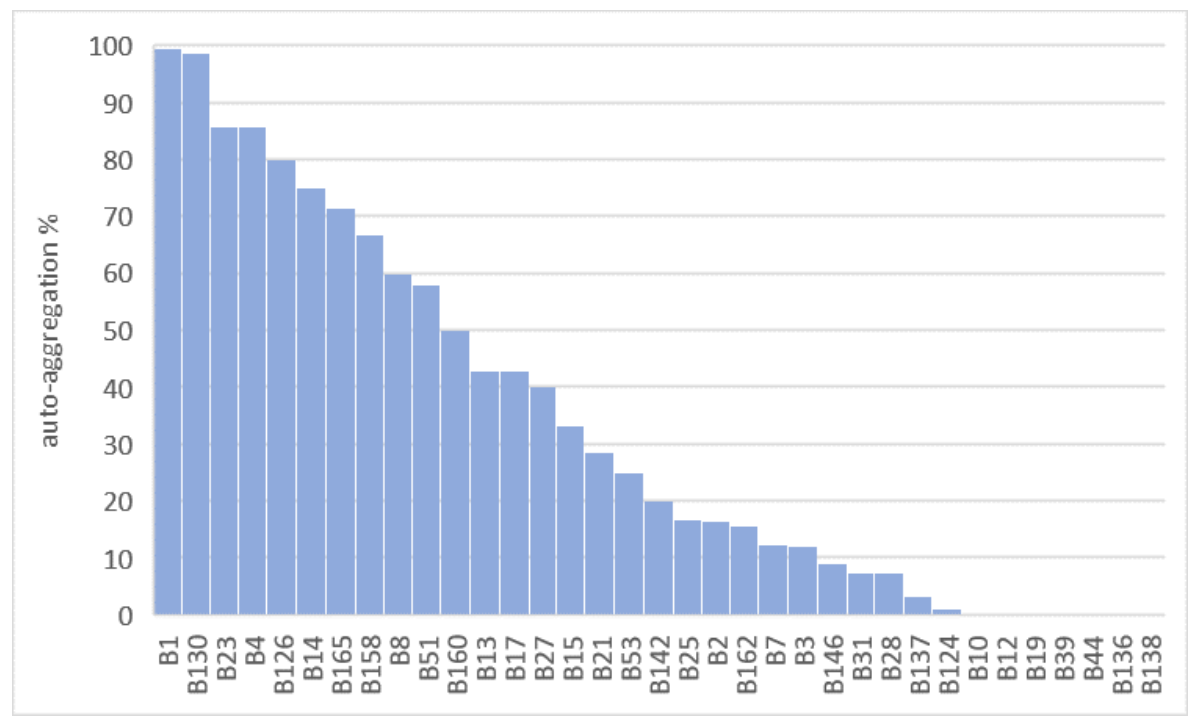

Figure 2. Distribution of the auto-aggregation assay.

L. plantarum B1 was chosen to inoculate jar B as a single starter because, in addition to possessing a $\beta$-glucosidase gene [11], it has a marked oleuropeinolytic activity and grows well at high concentrations of $\mathrm{NaCl}$ (e.g., 8\%: the initial concentration of the fermentation brine) [10] (to underline, the strain is mentioned with the name 'B21' in previous cited works). However, because B1 is sensitive to different phages found in fermentation brines, we thought of inserting it in a multiple starter, together with two other strains of L. plantarum (B51 and B124) already tested for different pro-technological activities in previous works $[11,25]$. This multiple starter was chosen to inoculate jar C. The choice of a multiple starter was suggested by the synergic activity of the selected strains in carrying out the debittering process, together with their resistance to phage attacks. L. plantarum B51 is a good producer of D/L lactate, and resists acidic $\mathrm{pH}$ because it produces lactic acid, reduces the $\mathrm{pH}$ of the medium, and grows in a strongly acidic environment. There was evidence of B51 (as well as B124) being resistant to various phages [25]. This strain demonstrated the ability to hydrolyze both sodium glycodeoxycholate (GDCA) and sodium taurodeoxycholate (TDCA) (Table 2). It proved to be resistant to kanamycin (MIC value of $512 \mu \mathrm{g} / \mathrm{mL}$ ), gentamicin (MIC value of $32 \mu \mathrm{g} / \mathrm{mL}$ ) and ampicillin (MIC value of $16 \mu \mathrm{g} / \mathrm{mL}$ ), and susceptible to others (Table 2). L. plantarum B124 has pro-technological characteristics, like B51, but it does not possess probiotic characteristics.

\subsection{Monitoring of Fermentation}

The viability of lactic acid bacteria and the trend of the growth of the Enterobacteriaceae population during the starter-driven and spontaneous fermentations are summarized in Figure 3.

In this study, the spontaneous LAB (Figure 3a) in jar A disappeared at 5 months of fermentation, so there was no natural starter to improve the olive fermentation for the biological debittering test. In jar B, inoculated with strain B1, the LAB population decreased after 6 months of the fermentation process, probably due to phage attacks. In jar C, which was inoculated with three different strains, the evolution of the lactic microflora ranged, but it never disappeared. It is evident how the inoculated starter managed to alternate the growth. The Enterobacteriaceae at the beginning of the process (after 10 days of the fermentation) were detected at an average of $4.2 \log \mathrm{CFU} / \mathrm{mL}$ in jar A (not inoculated), while it 
was 3.0-3.5 $\log \mathrm{CFU} / \mathrm{mL}$ in the jars inoculated (B and C) (Figure 3b). The enterobacteria rapidly decreased in all of the jars, and were not detected after 20 days of fermentation in jar $\mathrm{C}$, indicating the usefulness of the combined starter. In all of the jars was found a concomitant growth of yeasts in the end phase of the fermentation. The yeasts reached similar values $(4.9 \log \mathrm{CFU} / \mathrm{mL}$ in jar A; $5.0 \log$ $\mathrm{CFU} / \mathrm{mL}$ in jar B; $5.4 \log \mathrm{CFU} / \mathrm{mL}$ in jar D). Since there are some yeasts that produce both lactic acid and ethanol during fermentation, the acidity and $\mathrm{pH}$ of the fermentation environment could be influenced by these microorganisms.

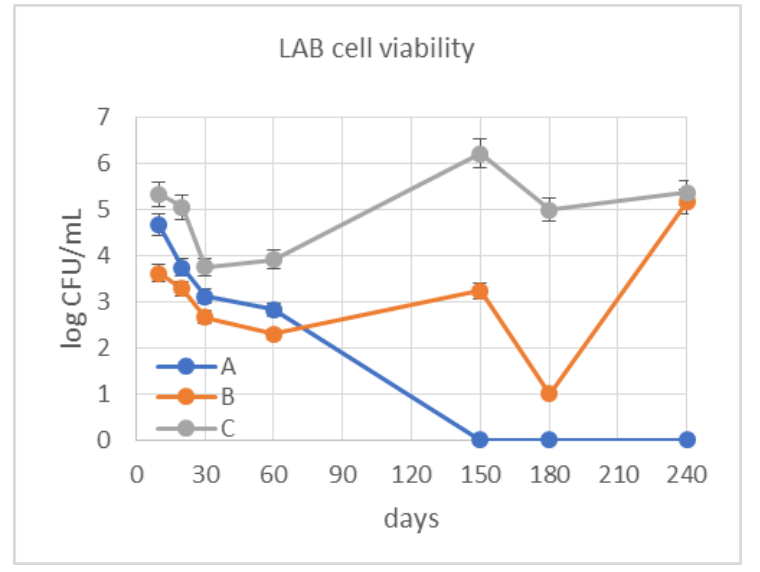

(a)

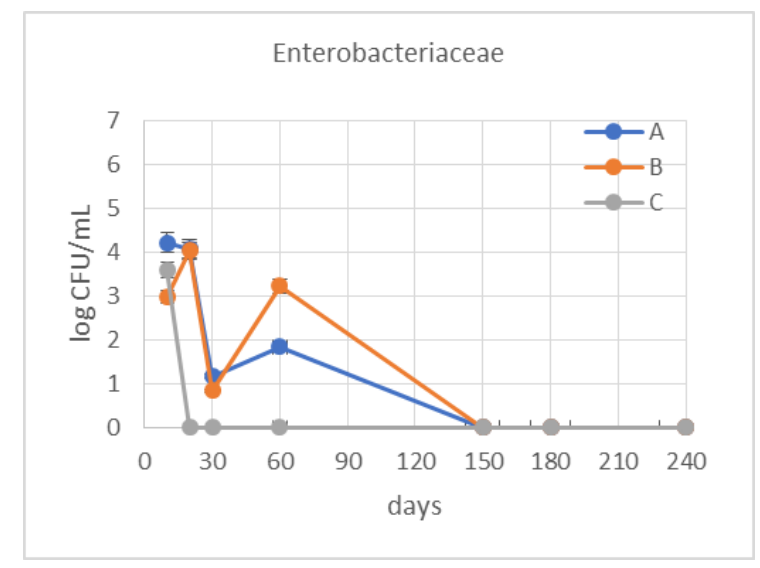

(b)

Figure 3. LAB cells' viability (a) and the trend of the growth of Enterobacteriaceae (b) during the fermentation. A = spontaneous; B = inoculated with L. plantarum B1; C = inoculated with L. plantarum $\mathrm{B} 1+\mathrm{B} 51+\mathrm{B} 124$. The data are expressed as mean of two replicates \pm standard deviation.

The trend of the growth of the LAB that was just described is also explained by Figures 4-6.

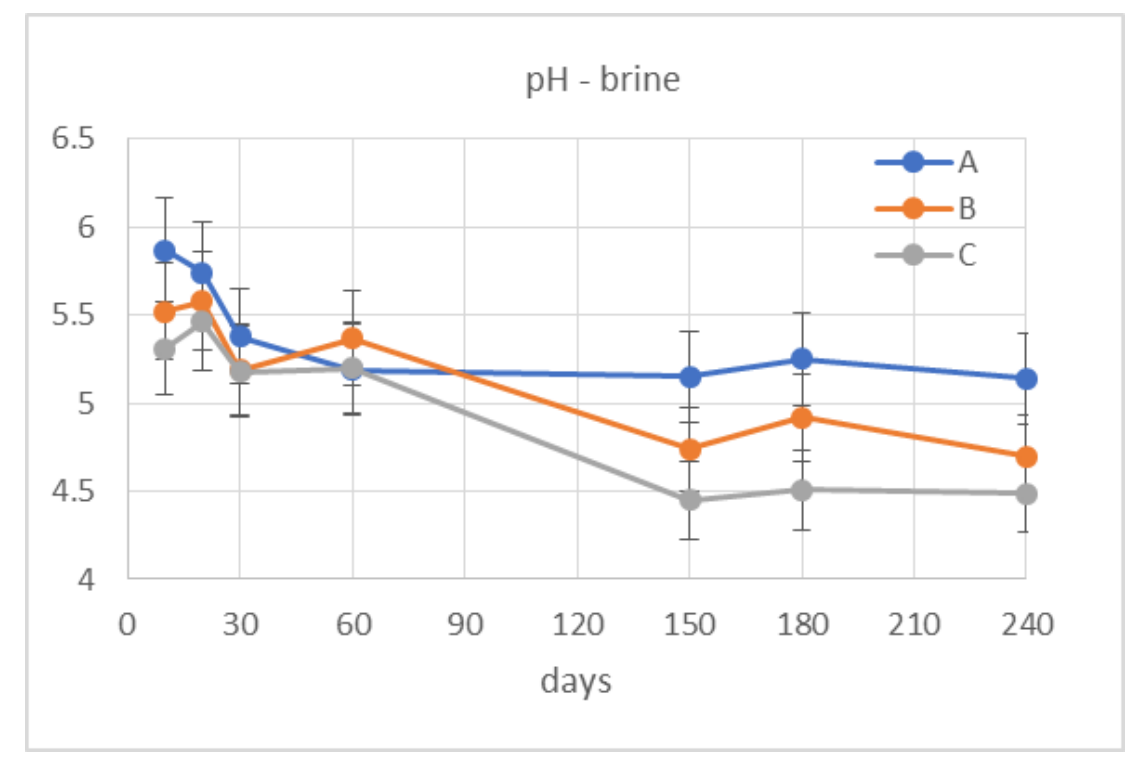

Figure 4. Evaluation of the $\mathrm{pH}$ in the brine during the fermentation. $\mathrm{A}=$ spontaneous; $\mathrm{B}=$ inoculated with L. plantarum B1; C = inoculated with L. plantarum B1 + B51 + B124. The data are expressed as the mean of two replicates \pm standard deviation.

The $\mathrm{pH}$ trend (Figure 4) in jars B and C purely decreases towards $\mathrm{pH} 4.5$ values at the end of fermentation. In jar $\mathrm{A}$, the $\mathrm{pH}$ never dropped below 5 , especially after the fifth month, when the LAB disappeared. 


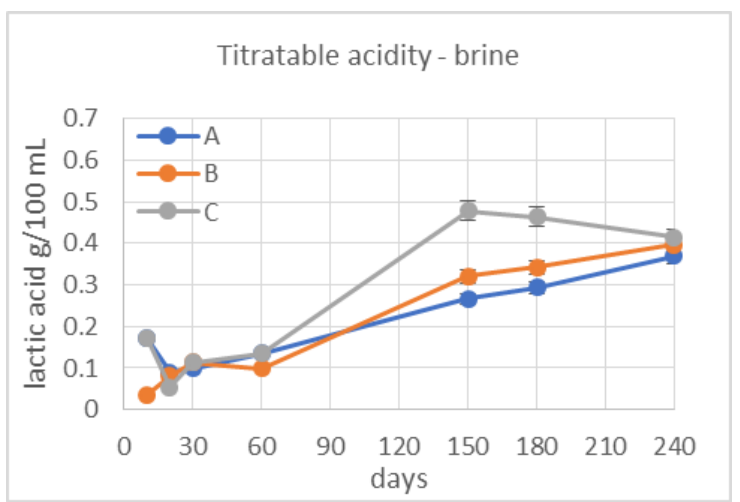

(a)

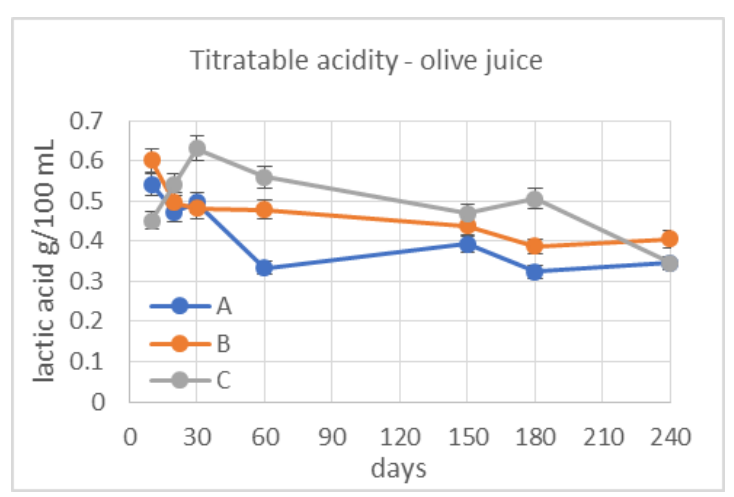

(b)

Figure 5. Evaluation of the titratable acidity in the brine (a) and in the olive juice (b) during the fermentation. $\mathrm{A}=$ spontaneous; $\mathrm{B}=$ inoculated with $\mathrm{L}$. plantarum $\mathrm{B} 1 ; \mathrm{C}=$ inoculated with $\mathrm{L}$. plantarum $\mathrm{B} 1+\mathrm{B} 51+\mathrm{B} 124$. The data are expressed as the mean of two replicates \pm standard deviation.

The titratable acidity of the brine (Figure 5a) ranged from 0.171 to 0.293 (expressed as lactic acid $\mathrm{g} / 100 \mathrm{~mL}$ brine) for jar A, from 0.036 to 0.396 for jar B, and from 0.171 to 0.414 for jar C. A significant increase of lactic acid concentration was noticed only after two months from the beginning of the test for all of the samples, reaching —at the end of the fermentation-similar value in all of the jars. The titratable acidity of the olive juice (Figure $5 b$ ) ranged from 0.541 to 0.345 (lactic acid g/100 mL olive juice) for jar A, from 0.601 to 0.404 for jar B, and from 0.451 to 0.345 for jar C. Jars A and B showed a continuous decrease; in jar $C$, it was observed only after one month, reaching the same value at the end of the fermentation as in jar A.

The initial salt concentration in the brine (Figure 6a) was $8 \%$ and, ten days after pickling, dropped to values of around $6 \%$ in all three jars: $5.973 \mathrm{~g} / 100 \mathrm{~mL}$ in jar A, $6.029 \mathrm{~g} / 100 \mathrm{~mL}$ in jar B, and $5.973 \mathrm{~g} / 100 \mathrm{~mL}$ in jar $\mathrm{C}$. During the first two months of the fermentation, the $\mathrm{NaCl}$ concentration trend appeared to be similar for the three jars, reaching values about 5.0. The salt continued to decrease in jar A until it reached a value of $5.297 \mathrm{~g} / 100 \mathrm{~mL}$ at the end of the fermentation. Jars $B$ and $C$ continued to display the same trend until they reached values of $5.719 \mathrm{~g} / 100 \mathrm{~mL}$ and $5.663 \mathrm{~g} / 100 \mathrm{~mL}$, respectively, at the end of the test.

In response to the osmotic effect, the $\mathrm{NaCl}$ concentration in the olive juice (Figure $6 \mathrm{~b}$ ) showed the opposite trend (from $2.254 \mathrm{~g} / 100 \mathrm{~mL}$ to $5.437 \mathrm{~g} / 100 \mathrm{~mL}$ for jar A, from $1.916 \mathrm{~g} / 100 \mathrm{~mL}$ to $5.775 \mathrm{~g} / 100 \mathrm{~mL}$ from jar B, and from $2.592 \mathrm{~g} / 100 \mathrm{~mL}$ to $6.000 \mathrm{~g} / 100 \mathrm{~mL}$ from jar C).

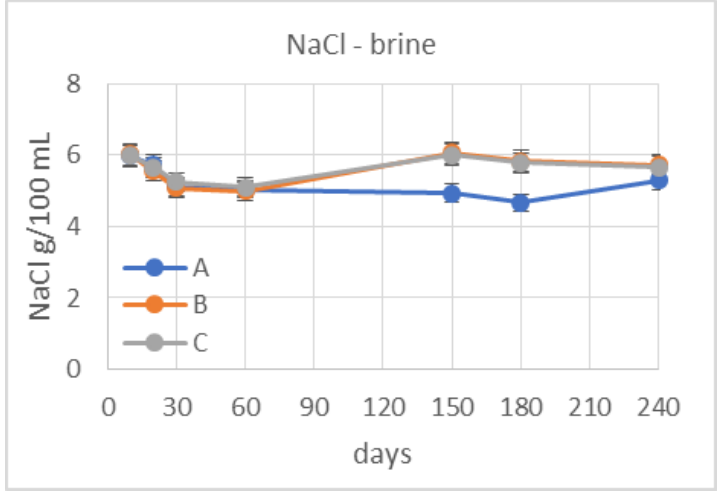

(a)

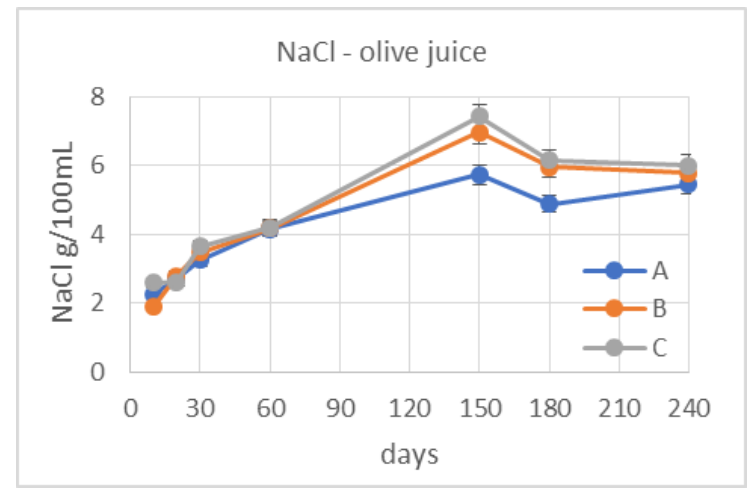

(b)

Figure 6. Evaluation of $\mathrm{NaCl}$ concentration in the brine (a) and in the olive juice (b) during fermentation. $\mathrm{A}=$ spontaneous; $\mathrm{B}=$ inoculated with L. plantarum $\mathrm{B} 1 ; \mathrm{C}=$ inoculated with L. plantarum $\mathrm{B} 1+\mathrm{B} 51+\mathrm{B} 124$. The data are expressed as the mean of two replicates \pm standard deviation. 


\subsection{De-Bittering Process}

The phenolic compounds present in the olive fruit are principally phenolic alcohols, such as the 3,4-(dihydroxyphenyl)ethanol (3,4-DHPEA or hydroxytyrosol) and the $p$-(hydroxyphenyl)ethanol ( $p$-HPEA or tyrosol); secoiridoid glucosides, such as oleuropein and ligstroside; and derivative aglycones, such as the dialdehydic form of decarboxymethyl elenolic acid linked to hydroxytyrosol (3,4-DHPEA-EDA), called oleacein, the dialdehydic form of decarboxymethyl elenolic acid linked to tyrosol ( $p$-HPEA-EDA), called oleocanthal, the 3,4-(dihydroxyphenyl)ethanol elenolic acid (3,4-DHPEA-EA and 3,4-DHPEA-EA, $\mathrm{H}$ ), called the isomers of oleuropein-aglycon, and the $p$-(hydroxyphenyl)ethanol elenolic acid ( $p$-HPEA-EA and $p$-HPEA-EA, $\mathrm{H}$ ), or isomers of ligstroside-aglycon [31].

In Figure 7 is shown the degradation of oleuropein into its derivatives (hydroxytyrosol, 3,4-DHPEA-EDA or oleacein, 3,4-DHPEA-EA and 3,4-DHPEA-EA, H).

The selected inoculants reduced the debittering time; in jars $B$ and $C$, hydroxytyrosol, the major compound derived from oleuropein degradation, was produced faster than jar A. In jar $C$, the highest level of hydroxytyrosol was reached, and this is probably due to the action of the mix of L. plantarum strains (Figure 7). After 20 days from the start of the fermentation, we detected values of about $900 \mathrm{mg} / \mathrm{kg}$ of hydroxytyrosol in Jar C. Initially, the hydroxytyrosol which was formed was retained in the pulp; subsequently, a sort of osmotic balance is established between the pulp and the brine, so it begins to diffuse into the brine. The isomers of oleuropein aglycon remain at constant levels in all of the samples showing low values. Only 3,4-DHPEA-EA, H increases after 10/20 days from the start of the fermentation, simultaneously to the production of hydroxytyrosol, probably due to the intensification of the de-bittering process.

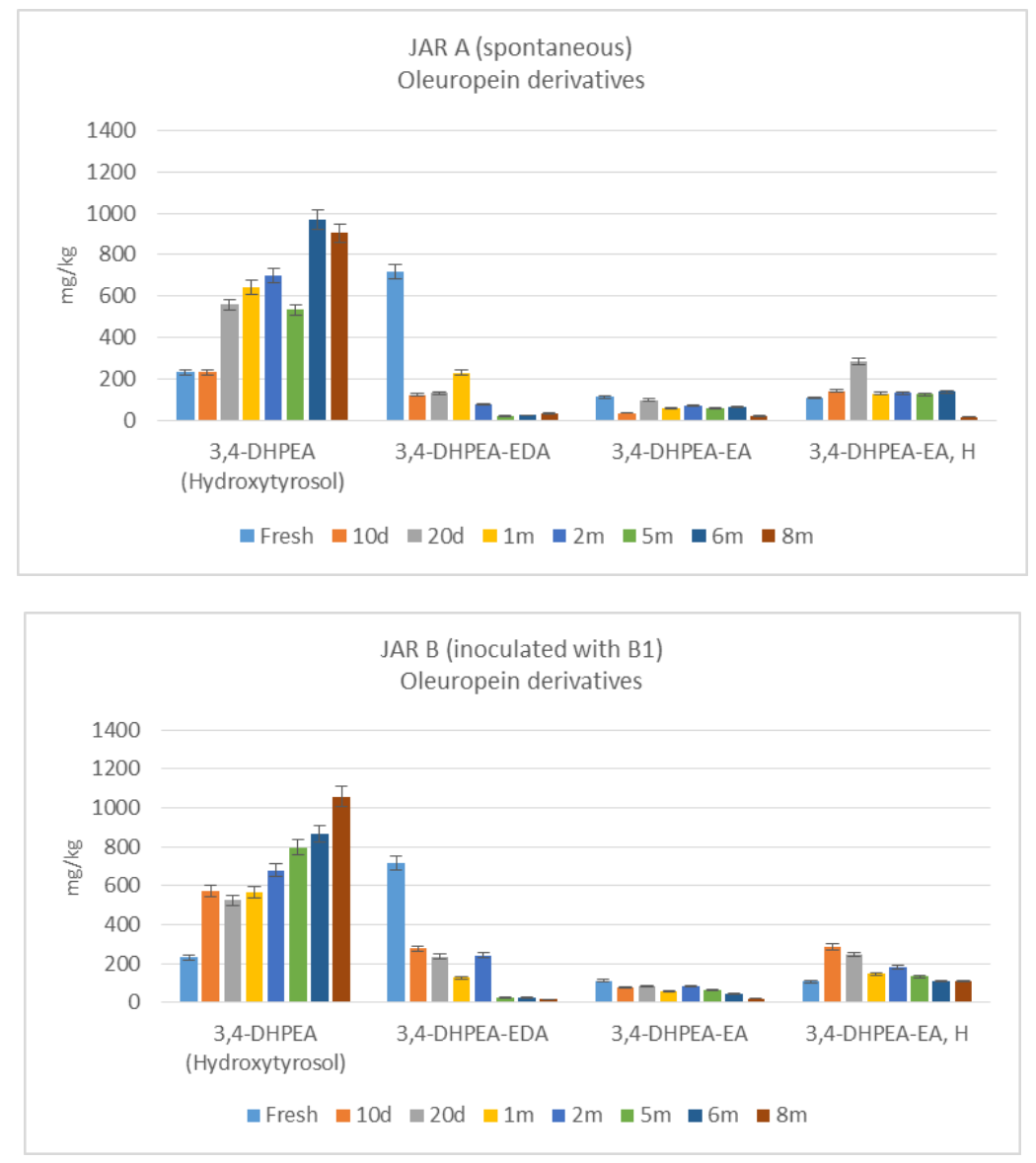

Figure 7. Cont. 


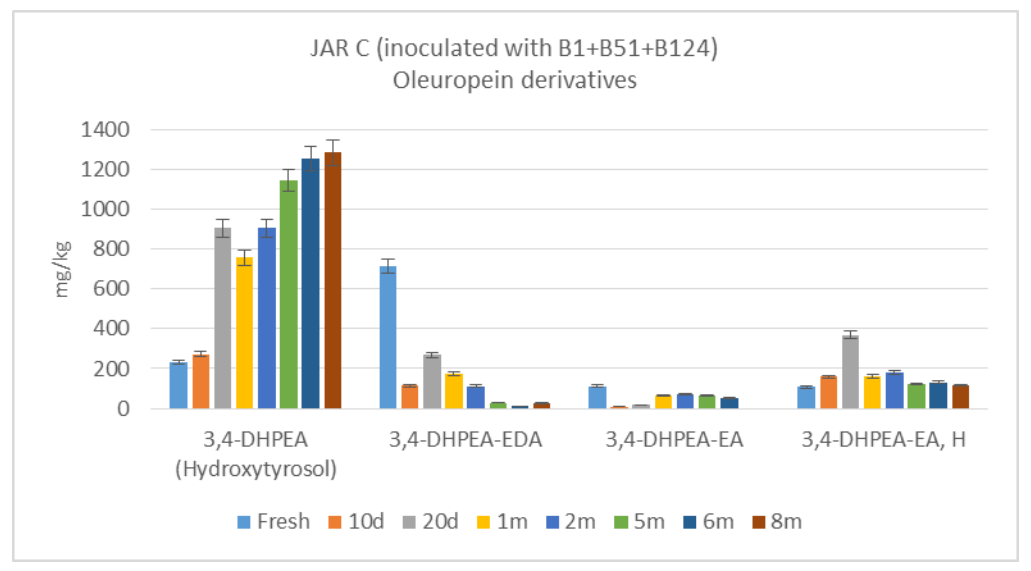

Figure 7. Oleuropein derivatives in the olive flesh during the fermentation.

Figure 8 shows the degradation of ligstroside into its derivatives (tyrosol, $p$-HPEA-EDA or oleocanthal, $p$-HPEA-EA and $p$-HPEA-EA, H). With regard to degradation of ligstroside, a high production of ligstroside-aglycons from the first days of the fermentation is noticeable, which is not followed by a high production of tyrosol. The aglycon accumulation in the flesh is more abundant in jar C. Tyrosol accumulates only at the end of fermentation.

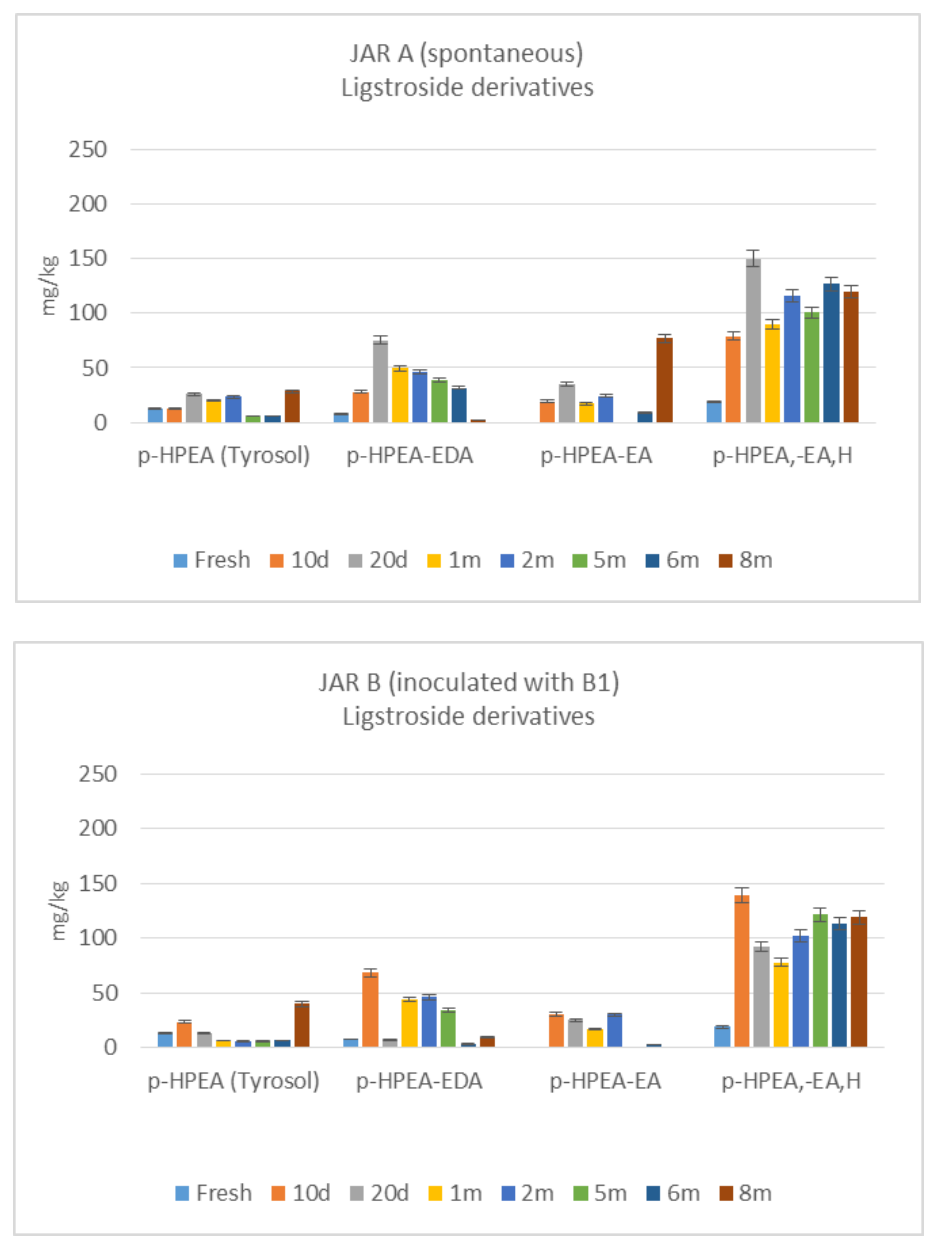

Figure 8. Cont. 


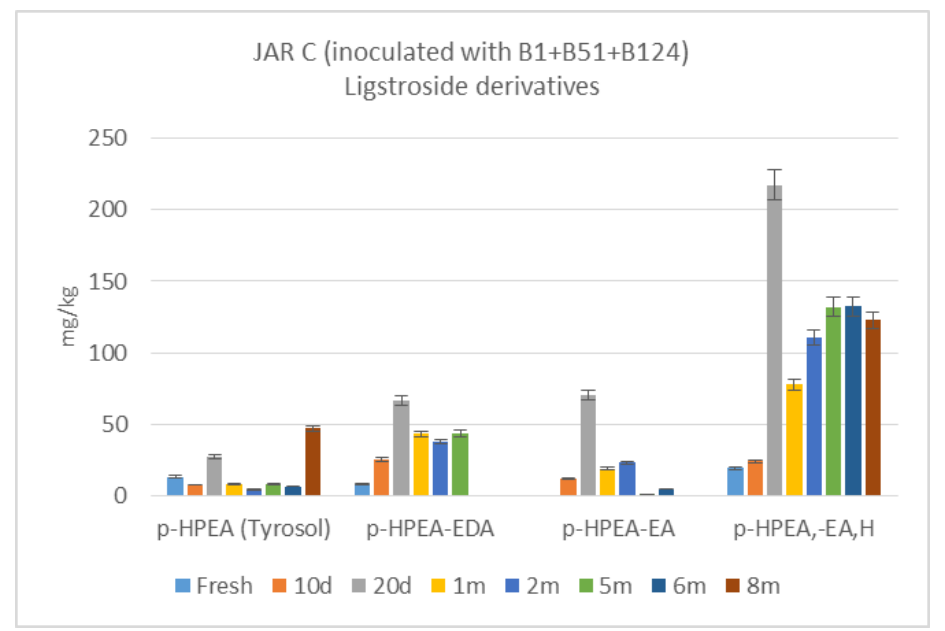

Figure 8. Ligstroside derivatives in the olive flesh during the fermentation.

Figure 9 shows the evolution of hydroxytyrosol and tyrosol in the oil fraction (Figure 9a) and in the brine (Figure $9 b$ ).

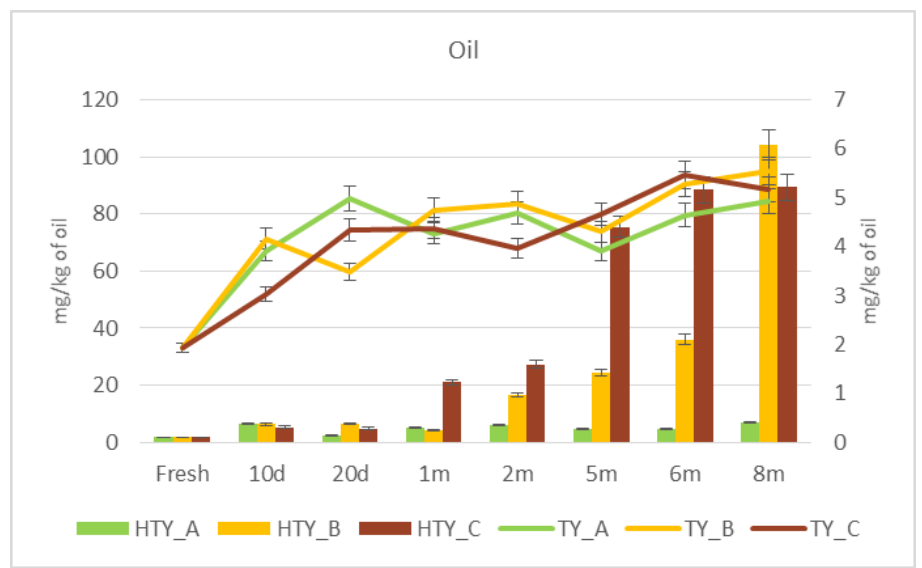

(a)

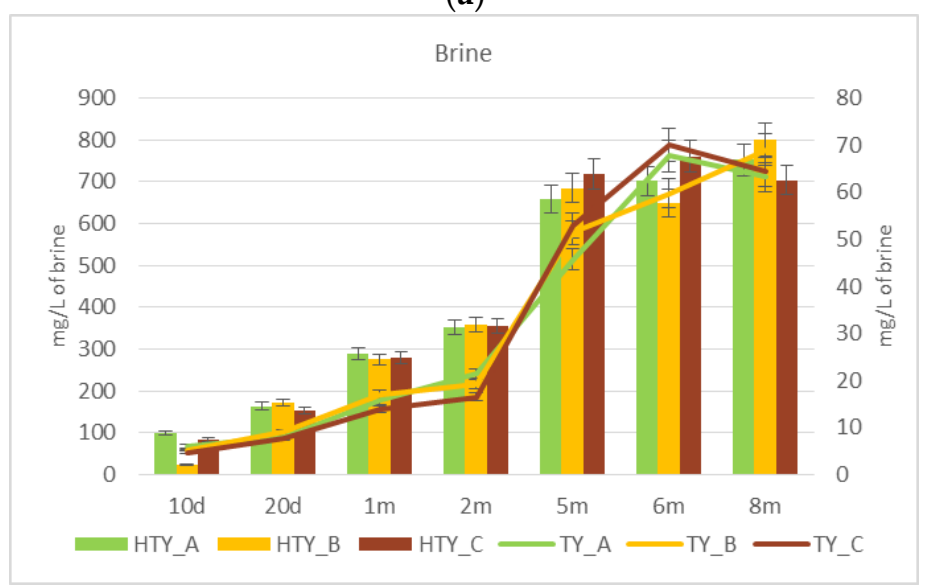

(b)

Figure 9. Hydroxytyrosol (HTY) and tyrosol (TY) in the oil fraction (a) and the brine (b) during the fermentation.

In the oil, the hydroxytyrosol gradually increased until it reached about $35 \mathrm{mg} / \mathrm{kg}$ in jar B and $90 \mathrm{mg} / \mathrm{kg}$ in jar C (Figure 9a). The increase was about 50-fold and 60-fold, respectively (Table 3). Instead, in jar A, the content of the HTY remained practically unchanged compared to the initial value 
(Figure 9a). In the brine, the trend of the hydroxytyrosol accumulation was the same for all three jars (Figure 9b).

The tyrosol enrichment in the oil was similar in all of the jars, and reached $5-6 \mathrm{mg} / \mathrm{kg}$ oil (Figure 9a). This increment is quantifiable as 2.5-3 fold the initial value (Table 3). Furthermore, in the brine, the tyrosol accumulation was progressive and similar in all of the jars, reaching about $60-70 \mathrm{mg} / \mathrm{L}$ values (Figure 9b).

Table 3. N-fold increase of hydroxytyrosol (HTY) and tyrosol (TY) in the different fractions (flesh, oil and brine) at the end of the de-bittering process, with respect to the initial concentration.

\begin{tabular}{ccccccc}
\hline & \multicolumn{2}{c}{ Flesh } & \multicolumn{2}{c}{ Oil } & \multicolumn{2}{c}{ Brine } \\
\cline { 2 - 7 } & HTY & TY & HTY & TY & HTY & TY \\
\hline Jar A & 3.9 & 2.2 & 3.8 & 2.5 & 7.7 & 10.5 \\
Jar B & 4.6 & 3.1 & 57.8 & 2.9 & 33.3 & 13.3 \\
Jar C & 5.5 & 3.6 & 49.4 & 2.7 & 8.4 & 13.3 \\
\hline
\end{tabular}

\section{Discussion}

One of the most important aspects of the improvement of the quality of table olives concerns the quality of the fermentation, which can be implemented through the use of starter cultures of lactic acid bacteria (LAB), selected according to their specific technological properties, capable of starting and driving the fermentation by taking over from the indigenous microflora that are already present on the drupes [32]. In 1994, the Table Olives Division of CREA-IT started to isolate and store strains of microorganisms from the fermentation and conditioning brines of table olives, carposphere, and phylloplane of Olea europaea L., with the aim of being able to use them for the biological de-bittering of olives [10,11,33-35]. The Collection of microorganisms of CREA-IT consists of 65 molecularly-identified and typed strains (35 of L. plantarum, 17 of L. pentosus and 13 of Leuconostoc mesenteroides) and, recently, was included in the World Data Center for Microorganism (WDCM 945). Italian food companies engaged in the production of fermented table olives have inadequate microbiological knowledge, and therefore are still linked to the classic natural fermentation. In this context, the existence of a collection of strains that are well characterized from a technological point of view, and that are isolated from the matrix itself to be transformed (the olive) can provide the basis for the development of starter culture systems which, while fully compatible with the typicality of the products, can guarantee the achievement of high and constant quality standards. In recent years, the industry of transformation also showed a growing interest in the use of selected enzymes especially for probiotic activity [36]. The term 'probiotic microorganisms' refers to live microorganisms and/or their components or metabolic products which, if taken in adequate quantities, can protect or promote the host's defenses by both directly and indirectly stimulating the defense mechanisms. Some researchers have patented 'table olives containing probiotic microorganisms' using L. paracasei to colonize olives that have already been de-bittered [37]. The aim of our research was to standardize a process of the transformation (fermentation) of table olives that require the use of lactic bacteria, which in addition to possessing oleuropeinolytic activity (i.e., capable of breaking down the compound responsible of bitter, oleuropein, in non-bitter compounds, such as hydroxytyrosol and elenolic acid, thanks to the action of $\beta$-glucosidase and esterase enzymes) also possess probiotic activity. The association of strains that are also able to confer to the product a probiotic quality, and to improve its sensory profile, would make olives, or derivative products such as patè, real 'functional foods'. Compared to the past, the consumer is increasingly attracted to table olives that have been naturally transformed. Moreover, in recent years, a growing interest stands out in the development of non-dairy probiotic products [38]. Fruits and vegetables have nutrients, such as glycosides, which promote the growth of probiotic cultures. In addition to olives, there are many fermented vegetables that can carry probiotic microorganisms, for example, 'sauerkraut', a fermented food made primarily from 
cabbage [39], or 'boza', a low-alcohol cereal-fermented beverage produced in the Balkan peninsula, which are very rich in probiotic LAB [40].

Lactobacilli are the dominant microorganisms in the fermentation of olives; they can produce high amount of organic acids and $\mathrm{H}_{2} \mathrm{O}_{2}$, that allow the maintenance of an environment that limits the growth of pathogens [1]. Several studies have also highlighted the viricidal activity of some strains, mainly due to their high acidification capacity and their ability to produce an arsenal of antimicrobial substances (organic acids, hydrogen peroxide, antifungal peptides, and bacteriocins) [41,42]. Their important role in the rheology and texture properties of fermented food products through the production of aromatic compounds and organic acids should also be emphasized [43].

In the present study, three different lab-scale fermentations of Olea europaea L. Itrana cv. olives were analyzed, with and without the addition of starters, and their microbiological and chemical profiles were described. The L. plantarum strains used as starter were tested in vitro for their phenotypic characteristics related to probiotic traits. The spontaneous LAB in jar A disappeared after 5 months of fermentation, so there was not any natural starter to improve the olive fermentation in the biological debittering test. The decrease of strain B1 after 6 months of the fermentation process was probably due to phage attacks. The presence of bacteriophages in the brine could be one cause of the inhibition of the starter culture that produces abnormal fermentations and/or the failure of the acidification process carried out by the lactic acid bacteria with more or less serious impact on the final product's characteristics, which then becomes the real obstacle to the use of starter cultures as inoculum [25]. The complex microbial composition of a multiple starter could support the phage attack because resistant strains could prevail over sensitive strains. The multiple starter inoculated into jar $C$ was the only one that was able to guide the fermentation until the end of the process (about 8 months), probably due to the alternation of the strains during the technological process. The microbiological component influences and responds to the fundamental variables of the fermentation process, such as $\mathrm{pH}$, acidity, and $\mathrm{NaCl}$ concentration. The jars inoculated with L. plantarum (B and C) showed lower values of $\mathrm{pH}$ in their brine than jar $\mathrm{A}$, reaching values between 4.5 and 5 , which are necessary to prevent an excessive growth of Gram-negative bacteria. An evident increase of brine acidity was noticed after two months from the beginning of the test for all of the samples, confirming the tolerance to high acidity of the natural and inoculated microorganisms, and their good lactic acid production. Enterobacteriaceae rapidly decreased in all of the jars and, in particular, were not detected after 20 days of fermentation in jar $C$, indicating the usefulness of the combined starter. Our results agree with those of other authors [20,44].

The results obtained demonstrated the ability of the chosen strains to grow in two different jars in the early stages of the fermentation, and they obtained a satisfactory outcome in the debittering and the polyphenol degradation. However, at the application level, the complex chemical composition of the fruit and the interactions that are established between the various water-soluble substances-in particular, between the phenolic substances and sodium chloride of the fermentation brines—can affect the bacterial biochemistry [34].

An increased concentration of hydrotyrosol was observed in several processed olives with oleuropeinolytic bacteria [42,44-46]. In green cracked Cypriot table olives, processed directly in brine as natural olives, the degradation of oleuropein was achieved faster in the presence of starter inoculants, whilst also producing higher levels of hydrotyrosol [44]. The loss of bio-phenols in the olive flesh depends upon the enzymatic activities of endogenous and microbial origin, and the diffusion to the brine due to osmotic dehydration. As reported by several authors, the olives exhibited a major loss in total phenols during the fermentation, mainly due to their degradation by LAB and secondarily due to their diffusion to the brine [20,44]. Additionally, 3,4-DHPEA-EDA or oleacein decreased during the sampling in all of the jars. This phenomenon was also observed by other authors [47]. The production of ligstroside-aglycons could be related to the same $\beta$-glucosidase activities involved in the production of oleuropein-aglycons, while the production of tyrosol is evidently due to a different esterase activity. 
In the jars inoculated with the starters, there was a much faster degradation of the secoiridoids than in the spontaneously-fermented jar. Moreover, in the inoculated jars, the production of hydroxytyrosol was higher than in the spontaneously-fermented jar, as well as the production of ligstroside aglycone. This indicated a complete degradation of oleuropein, and a partial degradation of the ligstroside.

\section{Conclusions}

In the present study, three strains of L. plantarum were selected with the aim of evaluating their ability to drive table olive fermentation. These strains were found to be good candidates for further investigation as starters in laboratory and industrial fermentations. In particular, the L. plantarum strain B51, isolated from olive brine, could be considered a promising probiotic candidate for obtaining probiotic food of completely vegetable origin. These probiotic table olives could be particularly helpful in all situations in which the administration of probiotic foods of animal origin is not applicable (i.e., lactose intolerants and vegans).

Author Contributions: Conceptualization, B.L., S.D.M., M.C.; methodology, B.L., M.Z.; validation, B.L., M.Z., F.T., B.B.; formal analysis, S.D.M., M.C., G.D.L., M.B., N.S., F.T., B.B.; data curation, B.L., M.Z., S.D.M., M.C., G.D.L.; writing—original draft preparation, B.L., S.D.M., M.C., N.S., G.D.L., M.B.; writing-review and editing, B.L., M.Z., S.D.M., M.C., N.S., G.D.L., M.B.; funding acquisition, B.L., N.S. All authors have read and agreed to the published version of the manuscript.

Funding: This research was supported by the projects INFOLIVA (D.M. 12479/2018) and DEAOLIVA (D.M. 93882/2017 and D.M. 35902/2019), funded by the Italian Ministry of Agricultural, Food and Forestry Policies (MiPAAF).

Conflicts of Interest: No potential conflict of interest was reported by the authors.

\section{References}

1. Perpetuini, G.; Prete, R.; Garcia-Gonzales, N.; Khairul Alam, M.; Corsetti, A. Table olives more than a fermented food. Foods 2020, 9, 178. [CrossRef] [PubMed]

2. Panagou, E.Z. Greek table olives processing. In Handbook of Vegetable Preservation and Processing, 2nd ed.; Hui, Y.H., Özgül Evranuz, E., Eds.; CRC Press: Boca Raton, FL, USA, 2015; pp. 547-550.

3. Lavermicocca, P.; Rossi, M.; Russo, F.; Srirajaskanthan, R. Table olives: A carrier for delivering probiotic bacteria to humans. In Olives and Olive Oil in Health and Disease Prevention, 1st ed.; Preedy, V.R., Watson, R.R., Eds.; Academic Press: London, UK, 2010; pp. 735-743.

4. Botta, C.; Langerholc, T.; Cencic, A.; Cocolin, L. In vitro selection and characterization of new probiotic candidates from table olive microbiota. PLoS ONE 2014, 9, e94457. [CrossRef] [PubMed]

5. Argyri, A.A.; Zoumpopoulou, G.; Karatzas, K.A.G.; Tsakalidou, E.; Nychas, G.J.E.; Panagou, E.Z.; Tassou, C.C. Selection of potential probiotic lactic acid bacteria from fermented olives by in vitro test. Food Microbiol. 2013, 33, 282-291. [CrossRef] [PubMed]

6. Bautista-Gallego, J.; Arroyo-Lopez, F.N.; Rantsiou, K.; Jimenez-Diaz, R.; Garrido-Fernandez, A.; Cocolin, L. Screening of lactic acid bacteria isolated from fermented table olives with probiotic potential. Food Res. Int. 2013, 50, 135-142. [CrossRef]

7. Guantario, B.; Zinno, P.; Schifano, E.; Rosselli, M.; Perozzi, G.; Palleschi, C.; Uccelletti, D.; Devirgiliis, C. In vitro and in vivo selection of potentially probiotic Lactobacilli from Nocellara del Belice table olives. Front. Microbiol. 2018, 9, 595. [CrossRef]

8. Oliveira, T.; Ramalhosa, E.; Nunes, L.; Pereira, J.A.; Colla, E.; Pereira, E.L. Probiotic potential of indigenous yeasts isolated during the fermentation of table olives from Northeast of Portugal. Innov. Food Sci. Emerg. Technol. 2017, 44, 167-172. [CrossRef]

9. Bonatsou, S.; Karamouza, M.; Zoumpopoulou, G.; Mavrogonatou, E.; Kletsas, D.; Papadimitriou, K.; Tsakalidou, E.; Nychas, G.-J.E.; Panagou, E.Z. Evaluating the probiotic potential and technological characteristics of yeasts implicated in cv. Kalamata natural black olive fermentation. Int. J. Food Microbiol. 2018, 271, 48-59. [CrossRef] 
10. Ciafardini, G.; Marsilio, V.; Lanza, B.; Pozzi, N. Hydrolysis of oleuropein by Lactobacillus plantarum strains associated with olive fermentation. Appl. Environ. Microbiol. 1994, 60, 4142-4147. [CrossRef]

11. Zago, M.; Lanza, B.; Rossetti, L.; Muzzalupo, I.; Carminati, D.; Giraffa, G. Selection of Lactobacillus plantarum strains to use as starters in fermented table olives: Oleuropeinase activity and phage sensitivity. Food Microbiol. 2013, 34, 81-87. [CrossRef]

12. Pino, A.; Vaccalluzzo, A.; Solieri, L.; Romeo, F.V.; Todaro, A.; Caggia, C.; Arroyo-López, F.N.; Bautista-Gallego, J.; Randazzo, C.L. Effect of sequential inoculum of beta-glucosidase positive and probiotic strains on brine fermentation to obtain low salt Sicilian table olives. Front. Microbiol. 2019. [CrossRef]

13. Ruiz-Barba, J.L.; Cathcart, D.P.; Warner, P.J.; Jimenez-Diaz, R. Use of Lactobacillus plantarum LPCO10, a bacteriocin producer, as a starter culture in Spanish-Style green olive fermentations. Appl. Environ. Microbiol. 1994, 60, 2059-2064. [CrossRef] [PubMed]

14. Brito, M.D.; Delgado, A.M.; Catulo, L.; Quintans, F.; Perese, C. The role of bacteriocin producers in table-olive fermentation. In Proceedings of the 5th International Symposium on Olive Growing, Izmir, Turkey, 27 September-2 October 2004.

15. Rubia-Soria, A.; Abriouel, H.; Lucas, R.; Ben Omar, N.; Martinez-Canamero, M.; Galvez, A. Production of antimicrobial substances by bacteria isolated from fermented table olives. World J. Microbiol. Biotechnol. 2006, 22, 765-768. [CrossRef]

16. Santos, M.M.; Piccirillo, C.; Castro, P.M.L.; Kalogerakis, N.; Pintado, M.E. Bioconversion of oleuropein to hydroxytyrosol by lactic acid bacteria. World J. Microbiol. Biotechnol. 2012, 28, 2435-2440. [CrossRef] [PubMed]

17. Ramirez, E.; Brenes, M.; de Castro, A.; Romero, C.; Medina, E. Oleuropein hydrolysis by lactic acid bacteria in natural green olives. LWT Food Sci. Technol. 2017, 78, 165-171. [CrossRef]

18. Rodríguez-Gómez, F.; Romero-Gil, V.; Arroyo-López, F.N.; Roldán-Reyes, J.C.; Torres-Gallardo, R.; Bautista-Gallego, J.; García-García, P.; Garrido-Fernández, A. Assessing the challenges in the application of potential probiotic lactic acid bacteria in the large-scale fermentation of Spanish-style table olives. Front. Microbiol. 2017, 8, 915. [CrossRef]

19. Heperkan, D. Microbiota of table olive fermentations and criteria of selection for their use as starters. Front. Microbiol. 2013, 4, 143. [CrossRef]

20. Paba, A.; Chessa, L.; Daga, E.; Campus, M.; Bulla, M.; Angioni, A.; Sedda, P.; Comunian, R. Do best-selected strains perform table olive fermentation better than undefined biodiverse starters? A comparative study. Foods 2020, 9, E135. [CrossRef]

21. FAO/WHO. Guidelines for the Evaluation of Probiotics in Food. 2002. Available online: www.fao.org (accessed on 5 April 2020).

22. Parker, E.A.; Roy, T.; D'Adamo, C.R.; Wieland, L.S. Probiotics and gastrointestinal conditions: An overview of evidence from the Cochrane Collaboration. Nutrition 2018, 45, 125-134.e11. [CrossRef]

23. Sniffen, J.C.; McFarland, L.V.; Evans, C.T.; Goldstein, E.J.C. Choosing an appropriate probiotic product for your patient: An evidence-based practical guide. PLoS ONE 2018, 13, e0209205. [CrossRef]

24. Arasu, M.V.; Al-Dhabi, N.A.; Ilavenil, S.; Choi, K.C.; Srigopalram, S. In vitro importance of probiotic Lactobacillus plantarum related to medical field. Saudi J. Biol. Sci. 2016, 23, S6-S10. [CrossRef]

25. Lanza, B.; Zago, M.; Carminati, D.; Rossetti, L.; Meucci, A.; Marfisi, P.; Russi, F.; Iannucci, E.; Di Serio, M.G.; Giraffa, G. Isolation and preliminary characterization of Lactobacillus plantarum bacteriophages from table olive fermentation. Ann. Microbiol. 2012, 62, 1467-1472. [CrossRef]

26. Tidona, F.; Zago, M.; Corredig, M.; Locci, F.; Contarini, G.; Giraffa, G.; Carminati, D. Selection of Streptococcus thermophilus strains able to produce exopolysaccharides in milk. Int. J. Dairy Technol. 2016, 69, 569-575. [CrossRef]

27. CODEX STAN 66-1981 (rev. 2013). Standard for Table Olives. Available online: http: //www.fao.org/fao-who-codexalimentarius/sh-proxy/en/?lnk=1\&url=https\%253A\%252F\%252Fworkspace. fao.org\%252Fsites\%252Fcodex\%252FStandards\%252FCXS\%2B66-1981\%252FCXS_066e.pdf (accessed on 25 January 2020). 
28. Lanza, B.; Di Serio, M.G.; Russi, F.; Iannucci, E.; Giansante, L.; Di Loreto, G.; Di Giacinto, L. Evaluation of the nutritional value of oven-dried table olives (cv. Majatica) processed by the Ferrandina style. Riv. Ital. Sostanze Gr. 2014, 2, 117-127.

29. IOC. Determination of Biophenols in Olive Oils by HPLC; COI/T.20/Doc No 29/Rev.1 2017; International Olive Council: Madrid, Spain, 2017.

30. Caggianiello, G.; Kleerebezem, M.; Spano, G. Exopolysaccharides produced by lactic acid bacteria: From health-promoting benefits to stress tolerance mechanisms. Appl. Microbiol. Biotechnol. 2016, 100, 3877-3886. [CrossRef]

31. Lanza, B.; Ninfali, P. Antioxidants in extra virgin olive oil and table olives: Connections between agriculture and processing for health choices. Antioxidants 2020, 9, 41. [CrossRef]

32. Aponte, M.; Blaiotta, G.; La Croce, F.; Mazzaglia, A.; Farina, V.; Settanni, L.; Moschetti, G. Use of selected autochthonous lactic acid bacteria for Spanish-style table olive fermentation. Food Microbiol. 2012, 30, 8-16. [CrossRef]

33. Marsilio, V.; Lanza, B.; Pozzi, N. Progress in table olives debittering: Degradation in vitro of oleuropein and its derivatives by L. plantarum. J. Am. Oil Chem. Soc. 1996, 73, 593-597. [CrossRef]

34. Marsilio, V.; Lanza, B. Characterization of an oleuropein degrading strain of Lactobacillus plantarum. Combined effect of compounds present in olive fermenting brines (phenols, glucose and $\mathrm{NaCl}$ ) on bacterial activity. J. Sci. Food Agric. 1998, 76, 520-524. [CrossRef]

35. Marsilio, V.; Seghetti, L.; Iannucci, E.; Russi, F.; Lanza, B.; Felicioni, M. Use of a lactic acid bacteria starter culture during green olive (Olea europaea L., cv. Ascolana tenera) processing. J. Sci. Food Agric. 2005, 85, 1084-1090. [CrossRef]

36. Petrova, P.; Petrov, K. Prebiotic-Probiotic Relationship: The Genetic Fundamentals of Polysaccharides Conversion by Bifidobacterium and Lactobacillus Genera. In Food Bioconversion, 1st ed.; Alexandru Grumezescu, A., Holban, A.M., Eds.; Academic Press: Cambridge, MA, USA; Elsevier: Amsterdam, The Netherlands, 2017.

37. Lavermicocca, P.; Lonigro, S.L.; Visconti, A.; De Angelis, M.; Valerio, F.; Morelli, L. Table Olives Containing Probiotic Microrganisms; Applicant CNR; EP1843664 B1 (8.7.2009); Granted European Patent Office: München, Germany, 2009.

38. Martins, E.M.F.; Ramos, A.M.; Vanzela, E.S.L.; Stringheta, P.C.; Pinto, C.L.O.; Martins, J.M. Products of vegetable origin: A new alternative for the consumption of probiotic bacteria. Food Res. Int. 2013, 51, 764-770. [CrossRef]

39. Zabat, M.A.; Sano, W.H.; Wurster, J.I.; Cabral, D.J.; Belenky, P. Microbial Community Analysis of Sauerkraut Fermentation Reveals a Stable and Rapidly Established Community. Foods 2018, 7, 77. [CrossRef] [PubMed]

40. Petrova, P.; Emanuilova, M.; Petrov, K. Amylolytic Lactobacillus strains from Bulgarian fermented beverage boza. Z. Naturforsch. C J. Biosci. 2010, 65, 218-224. [CrossRef]

41. Ruiz-Barba, J.L.; Caballero-Guerrero, B.; Maldonado-Barragán, A.; Jiménez-Díaz, R. Coculture with specific bacteria enhances survival of Lactobacillus plantarum $\mathrm{NC} 8$, an autoinducer-regulated bacteriocin producer, in olive fermentations. Food Microbiol. 2010, 27, 413-417. [CrossRef]

42. Hurtado, A.; Ben Othman, N.; Chammem, N.; Hamdi, M.; Ferrer, S.; Reguant, C.; Bordons, A.; Rozès, N. Characterization of Lactobacillus isolates from fermented olives and their bacteriocin gene profiles. Food Microbiol. 2011, 28, 1514-1518. [CrossRef] [PubMed]

43. Pérez Montoro, B.; Benomar, N.; Lavilla Lerma, L.; Castillo Gutiérrez, S.; Gálvez, A.; Abriouel, H. Fermented aloreña table olives as a source of potential probiotic Lactobacillus pentosus strains. Front. Microbiol. 2016, 7, 1583.

44. Anagnostopoulos, D.A.; Goulas, V.; Xenofontos, E.; Vouras, C.; Nikoloudakis, N.; Tsaltas, D. Benefits of the use of lactic acid bacteria starter in green cracked Cypriot table olives fermentation. Foods 2020, 9, 17. [CrossRef]

45. Kaltsa, A.; Papaliaga, D.; Papaioannou, E.; Kotzekidou, P. Characteristics of oleuropeinolytic strains of Lactobacillus plantarum group and influence on phenolic compounds in table olives elaborated under reduced salt conditions. Food Microbiol. 2015, 48, 58-62. [CrossRef] 
46. Iorizzo, M.; Lombardi, S.J.; Macciola, V.; Testa, B.; Lustrato, G.; Lopez, F.; De Leonardis, A. Technological potential of Lactobacillus strains isolated from fermented green olives: In vitro studies with emphasis on oleuropein-degrading capability. Sci. World J. 2016, 2016, 1917592. [CrossRef]

47. Servili, M.; Minnocci, A.; Veneziani, G.; Taticchi, A.; Urbani, S.; Esposto, S.; Sebastiani, L.; Valmorri, S.; Corsetti, A. Compositional and tissue modifications induced by the natural fermentation process in table olives. J. Agric. Food Chem. 2008, 56, 6389-6396. [CrossRef]

Publisher's Note: MDPI stays neutral with regard to jurisdictional claims in published maps and institutional affiliations.

(C) 2020 by the authors. Licensee MDPI, Basel, Switzerland. This article is an open access article distributed under the terms and conditions of the Creative Commons Attribution (CC BY) license (http://creativecommons.org/licenses/by/4.0/). 